\title{
Processing Parameters Optimization of Cotton Stalk (Gossypium hirsutum L.) Particleboards with Emulsifiable Polymeric Isocyanate Adhesive
}

\author{
Thanh Tung Nguyen, ${ }^{\mathrm{a}, \mathrm{c}, \mathrm{e} *}$ Adam Redman, ${ }^{\mathrm{d}}$ William Leggate, ${ }^{\mathrm{d}}$ Luigi-j Vandi, ${ }^{\mathrm{b}, \mathrm{c}}$ \\ Henri Bailleres, ${ }^{\mathrm{d}}$ and Michael Heitzmann ${ }^{\mathrm{a}, \mathrm{c}, *}$
}

\begin{abstract}
The compaction behavior of cotton stalk particle mats, temperature profile inside the particle mats, and influence of surface particle size were studied relative to the properties of three-layered cotton stalk particleboards. Modulus of rupture (MOR), modulus of elasticity (MOE), internal bond, and thickness swelling were used as a measure for mechanical and physical performance. Two types of cotton stalk particleboard were manufactured. Results indicated that compression stiffness of the particle mat increased with increasing particle size; however, it decreased with increasing mat moisture content and temperature. At mat moisture contents of $12 \%$ and $18 \%$, the plateau temperature at the centerline was not significantly different between boards having coarse and fine particles. However, the plateau time of boards with coarse particles was significantly lower than that of boards with fine particles. Additionally, thickness swelling of boards with a surface particle size of $2 \mathrm{~mm}$ was significantly lower than that of boards with surface particle size of $4 \mathrm{~mm}$. Boards with a surface particle size of $2 \mathrm{~mm}$ had MOR and MOE values $15 \%$ and $10 \%$ higher, respectively, than boards with surface particle size of $4 \mathrm{~mm}$. Internal bond decreased $6.5 \%$ with decreasing surface particle size from $4 \mathrm{~mm}$ to $2 \mathrm{~mm}$.
\end{abstract}

Keywords: Cotton stalks; Mat compaction behavior; Temperature behavior; Particleboards

Contact information: a: School of Mechanical and Mining Engineering, The University of Queensland, Brisbane, QLD 4072, Australia; b: School of Chemical Engineering, The University of Queensland, Brisbane, QLD 4072, Australia; c: Centre for Advanced Materials Processing and Manufacturing, The University of Queensland, Brisbane, QLD 4072, Australia; d: Queensland Department of Agriculture and Fisheries, Horticulture and Forestry Science, Salisbury Research Facility, 50 Evans Rd, Salisbury, QLD 4107, Australia; e: Research Institute of Forest Industry, Vietnamese Academy of Forest Sciences, 46 Duc Thang, North Tu Liem, Ha Noi, Vietnam;

*Corresponding authors: thanhtung.nguyen@uq.edu.au; m.heitzmann@uq.edu.au

\section{INTRODUCTION}

A global shortage of wood materials along with continuing population growth is motivating research in the utilization of agricultural residues as a new source of raw material to reduce pressure on diminishing forest resources. Cotton stalk residues have a comparable composition and structure to the most common hardwood species (Tutus et al. 2010; Soulama et al. 2015). Therefore, cotton stalks can be used as an alternative lignocellulosic material for the manufacturing of particleboard. Particles are subjected to different kinds of stress during the hot-press period. There are three main parameters, which have effects on the hot-pressing process, namely the mat moisture content, press closing rate, and press temperature. These factors have influences on the curing rate of resin, the development of the vertical density profile (density profile in the thickness direction), and bond quality; consequently, they will have impact on the mechanical and 
physical properties of the particleboard (Wong et al. 1998). Moreover, the combination of elevated temperature and high moisture content of the mat increase the chance of delamination, caused by excess steam pressure inside the board during pressing, when the press pressure is released (Dai and Wang 2004).

It is well known that the particle mat structure of three-layered particleboard results from a combination of three factors: (1) particle shape and dimension in the surface and core layers, (2) moisture content, and (3) resin content in the surface and core layers. These factors considerably influence the formation of the vertical density profile of the particleboard. Moreover, the density of wood materials has noticeable effects on the stressstrain relationship in the mat during hot-press application and hence leads to changes in the vertical density profile (Wang and Winistorfer 2000). In addition, wood type and particle size are known as factors that affect the performance of the particleboard, and they also determine the temperature behavior in the mat of particleboard during the hot-press period (Rofii et al. 2014).

In order to optimize the production process of particleboard made from cotton stalks, it is of critical importance to understand the influence of cotton stalk particle sizes, particle mat moisture content, and temperature on mat compaction behavior as well as temperature behavior in the mat during the hot-press stage. There are a number of published studies on manufactured particleboards from cotton stalk residues. Guler and Ozen (2004) investigated some properties of particleboards made from cotton stalk; however, the research did not mention the particle sizes used for the surface and core layers, with the results showing only that cotton stalks can be used as an alternative and valuable raw material for the manufacturing of particleboard. Kadja et al. (2011) studied the utilization of bone adhesive to produce particleboard from stems of cotton plants at a pressing temperature of $140{ }^{\circ} \mathrm{C}$. Again, the particle sizes were not mentioned in this study; the results revealed that the boards met requirements of the standard ANSI A208.1 (1999) in terms of MOR (modulus of rupture) and MOE (modulus of elasticity) values with the rate of bone resin applied at $10 \%$ and $12.5 \%$. The effects of some technological production variables on mechanical and physical properties of particleboard manufactured from cotton stalks were studied by Nazerian et al. (2015). In this investigation, the authors only mentioned that the cotton stalk was ground using a disc mill into particles usable for production of particleboard and the results showed that the MOR, MOE, and IB (internal bond) of boards increased with increasing board density and press temperature. Additionally, the increase in press closing speed resulted in increasing MOR but decreasing IB. Water absorption and thickness swelling decreased with increasing panel density and press temperature, while the press closing speed had an insignificant effect on water absorption and thickness swelling. Furthermore, all previous studies conducted on the manufacture of cotton-stalk particleboards mentioned above only considered cotton-stalk stems without bark as raw materials. The average stem (with bark) proportion accounted for just $46 \mathrm{wt} \%$ of the whole mass of cotton stalk (Nguyen at al. 2020). The average bark of cotton stems has been reported to be $26 \mathrm{wt} \%$ of cotton stem mass (Li et al. 2012). Removing bark from very thin cotton stems is also technically difficult and adds cost. Therefore, the utilization of whole cotton-stalk (including bark and branches) as raw materials represents a significant potential additional biomass. To the authors' knowledge, no studies have been conducted to understand the influence of cotton stalk particle sizes, particle mat moisture content, and temperature on mat compaction behavior as well as temperature behavior in the mat during the hot-press stage. 
The aims of this research were to investigate the effects of opening particle sizes (the size of the sieve was used to generate particles as mentioned in Fig. 1). For example, opening particle sizes of $8 \mathrm{~mm}$ means that particles had passed through sieve size of $8 \mathrm{~mm}$. Studies were conducted to determine the effects of particle size, particle mat moisture content, and temperature on the compression behavior of the particle mat. Further tests were done to evaluate the influences of particle sizes and moisture content of the particle mat on temperature behavior inside the mat of particleboard, and to optimize surface particle size.

\section{EXPERIMENTAL}

\section{Materials}

The cotton stalks used in this research were obtained less than 1 month after the cotton balls were harvested at Goodar, Queensland, Australia (WGS-84 coordinates: 28.4775 S, 150.2455 E). After harvesting, the cotton stalks were air-dried for two months to a moisture content of $20 \%$. Cotton ball residues have negative impacts on properties of boards (Nguyen at al. 2020). Therefore, cotton ball residues were separated from the cotton stalks. Subsequently, those stalks (stalks without cotton ball residues) were converted into chips using a commercial chipping machine (Hansa C7, Hansa Products Ltd., Hamilton, New Zealand). Subsequently, the chips were milled to three different particle sizes by a laboratory cutting mill (SM 100, Retsch Technology GmbH, Haan, Germany) using three different sieves: $8 \mathrm{~mm}, 4 \mathrm{~mm}$, and $2 \mathrm{~mm}$ (Fig. 1). Subsequently, these particles were shaken by using a $0.3-\mathrm{mm}$ sieve to remove particles with a size smaller than $0.3 \mathrm{~mm}$.

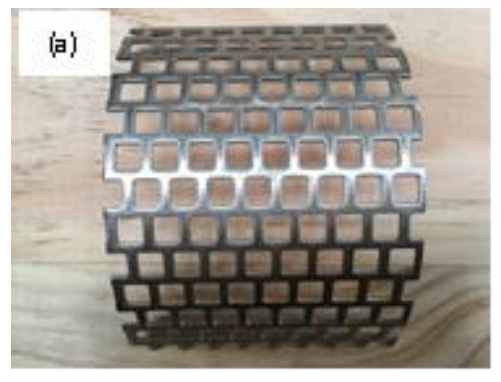

Fig. 1. Three different sieves: (a) $8 \mathrm{~mm}$, (b) $4 \mathrm{~mm}$, and (c) $2 \mathrm{~mm}$

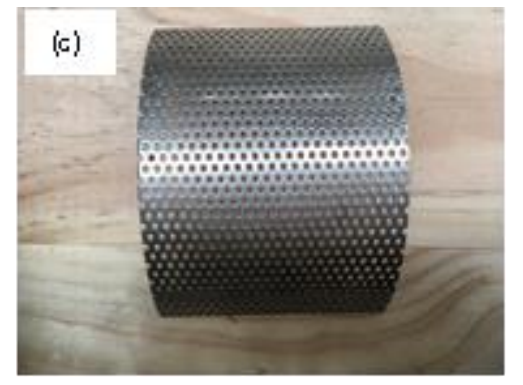

\section{Methods}

Particle mat compaction behavior

Particles that had passed through three different opening particle sizes $(8 \mathrm{~mm}, 4$ $\mathrm{mm}$, and $2 \mathrm{~mm}$ ) were used to investigate their compaction mat behavior at different moisture contents $(12 \%, 18 \%, 24 \%$, and $30 \%)$. The average moisture content at fiber saturation point (FSP) is approximately 30\%, and the change of moisture content below FSP has effects on wood properties. The experimental also involved different temperatures (room temperature, 50, 75, 100, 125, 150, and $170^{\circ} \mathrm{C}$ ). The particles were first conditioned at a temperature of $20{ }^{\circ} \mathrm{C}$ and $65 \%$ relative humidity $(\mathrm{RH})$ to reach an equilibrium moisture of $12 \pm 1 \%$. The particles with the moisture contents of $18 \%, 24 \%$, and $30 \%$ were obtained by spaying water on particles containing a moisture content of $12 \%$ with the calculated 
amount of water added in accordance with individual target moisture content and then placed in a sealed plastic bag for a week.

In order to study the particles' compression behavior, a compression mold was designed as shown in Fig. 2 with a plunger and cylinder diameter of $50 \mathrm{~mm}$. Holes with diameter of $1 \mathrm{~mm}$ were made on the sides of cylinder to ensure air and gases could escape easily during compression tests (Fig. 2).
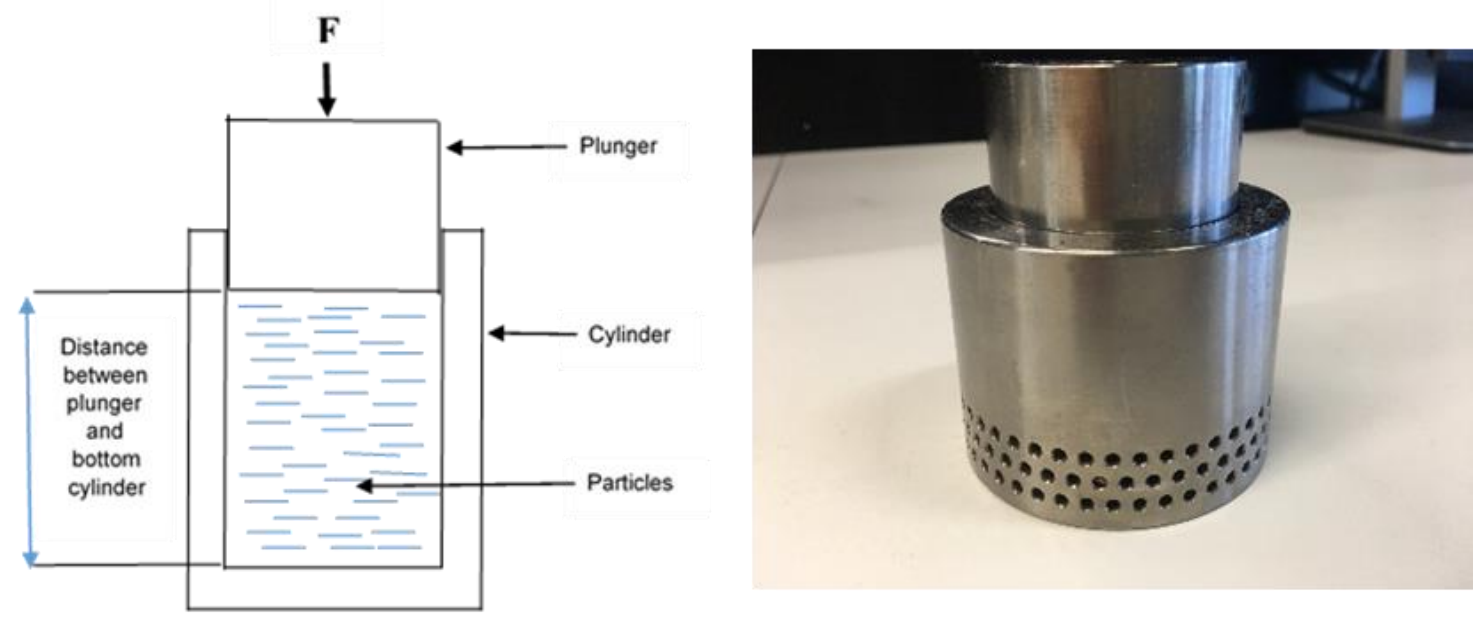

Fig. 2. Compression mold

For the compression at room temperature, $16.5 \mathrm{~g}$ of particles at different sizes and moisture contents were loaded into the compression mold, which was put in the compression cage (Fig. 3). The compression cage was set up inside the environmental chamber that allows a static temperature to be set. For the compression at higher temperatures, $16.5 \mathrm{~g}$ of particles at different sizes and moisture content were wrapped in aluminium foil and placed in the environmental chamber with the temperature set to the desired set-point to heat particles to the desired temperature. As soon as the particles reached the desired temperature, they were placed in the compression mold and the compaction behavior was measured.
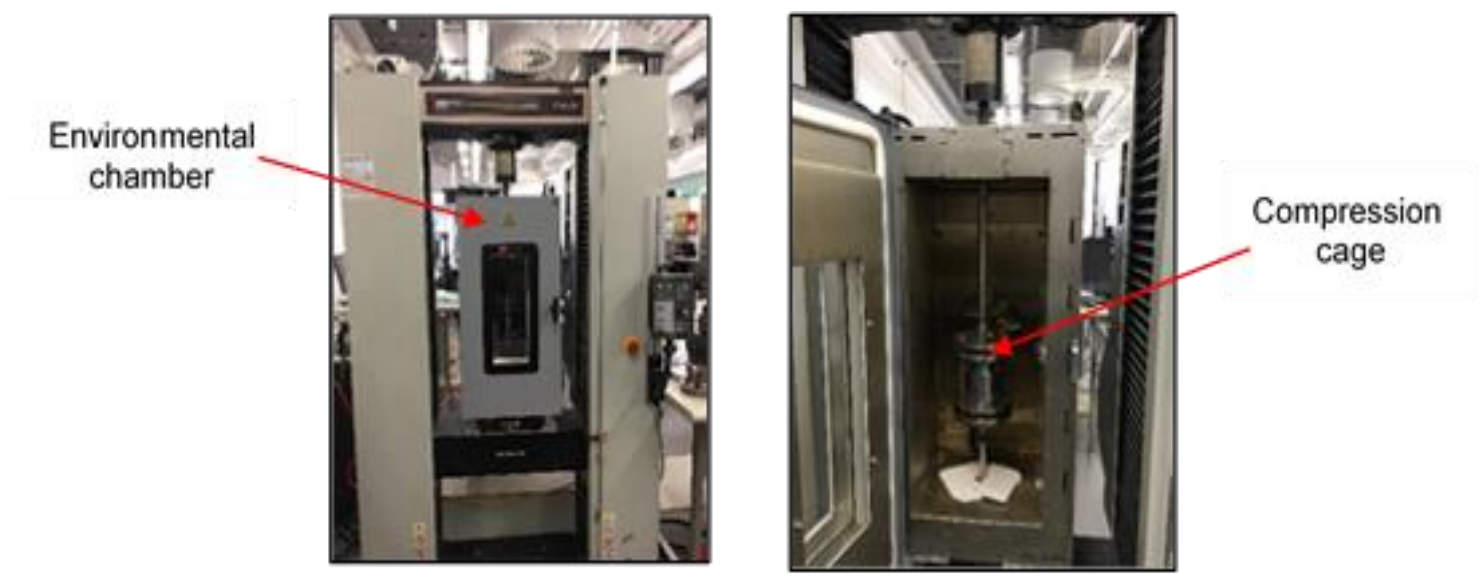

Fig. 3. Set-up for particles compression tests 
The compression test was conducted by using a universal testing machine (Instron 4505, Instron, Wycombe, England) (Fig. 3). The maximum load of $10 \mathrm{kN}$ was applied with a loading rate of $15 \mathrm{~mm} / \mathrm{min}$. Three replications were performed for each type of test.

During tests, the force and displacement were recorded. The specific pressure at the specific time during the testing period was calculated based on the recorded force at that moment and the plunger base area according to Eq. 1,

$$
P\left(\mathrm{~N} / \mathrm{mm}^{2}\right)=F / S
$$

where $P$ is specific pressure $\left(\mathrm{N} / \mathrm{mm}^{2}\right), F$ is force $(N)$, and $S$ is plunger base area $\left(\mathrm{mm}^{2}\right)$.

The density of the compacted mat was calculated based on the mat weight, plunger base area, and distance between the plunger and bottom cylinder according to Eq. 2 ,

$$
\gamma\left(\mathrm{g} / \mathrm{cm}^{3}\right)=\mathrm{m} / \mathrm{Sl}
$$

where $\gamma$ is density of compacted mat $\left(\mathrm{g} / \mathrm{cm}^{3}\right), m$ is mat weight $(\mathrm{g}), S$ is the plunger base area $\left(\mathrm{mm}^{2}\right)$, and $l$ is the distance between the plunger and bottom cylinder $(\mathrm{cm})$. The compression behavior of particle mats is visualized as a pressure - density diagram.

\section{Temperature behavior inside the mat of boards}

The aim of this investigation was to find the effect of particle size and mat moisture content on temperature profile according to the thickness direction, the nominal mat moisture content at $12 \%, 18 \%, 24 \%$, and $30 \%$. Particles were conditioned at a temperature of $20{ }^{\circ} \mathrm{C}$ and $65 \%$ relative humidity to reach an equilibrium moisture of $12 \%$. The particles with the moisture contents of $18 \%, 24 \%$, and $30 \%$ were obtained by spraying water on particles containing a moisture content of $12 \%$ with the calculated amount of water added in accordance with individual target moisture content and then placed in a sealed plastic bag for a week), and the three opening particle sizes $8 \mathrm{~mm}, 4 \mathrm{~mm}$, and $2 \mathrm{~mm}$ (particles were generated by using sieve sizes of $8 \mathrm{~mm}, 4 \mathrm{~mm}$, and $2 \mathrm{~mm}$ ), where the thickness of the board was $12 \mathrm{~mm}$, the target density was $0.75 \mathrm{~g} / \mathrm{cm}^{3}$ and the board size was $28 \mathrm{~cm} \times 32$ $\mathrm{cm}$. A press temperature and pressure of $170{ }^{\circ} \mathrm{C}$ and $3 \mathrm{MPa}$, were applied, respectively. Emulsifiable polymeric isocyanate adhesive (eMDI) I-BOND® PB EM 4352 (Huntsman Polyurethanes, Melbourne, Australia) was applied at a rate of $6 \%$ based on the oven-dry weight of the particles. The temperature behavior inside the mat according to thickness direction was measured at the surface and core (centerline) of the mat for both homogenous boards and three-layered boards. A type T thermocouple and a temperature measurement device (dataTaker DT80, Longtek Pty Ltd., Barcaldine, Australia) were used to conduct this investigation. Three replications were conducted for each type of measurement. The temperature curves displayed are the average ones.

For the three-layered particleboard, the surface layers were fine particles (2-mm opening particle size) and the core layers are coarse particles ( $8 \mathrm{~mm}$ opening particle size). The proportion between surface layers and core layers by particle weight was $45 \mathrm{wt} \%$ and $55 \mathrm{wt} \%$, respectively, for a board thickness of $12 \mathrm{~mm}$; following the recommended layup presented by $\mathrm{Fu}(1998)$

\section{Optimization of opening particle size for the surface layers}

The aim of this study was to evaluate the influence of opening particle size in the surface layers on mechanical and physical properties of three-layered cotton stalk particleboards. The best performing opening size particles $(8 \mathrm{~mm})$ in terms of mechanical 
performance from four coarse opening particle sizes, including $20 \mathrm{~mm}, 10 \mathrm{~mm}, 8 \mathrm{~mm}$, and $6 \mathrm{~mm}$, was chosen for the core layer for this study, based on work previously performed by Nguyen et al. (2020). Two opening particle sizes including $4 \mathrm{~mm}$ and $2 \mathrm{~mm}$ were selected for the surface layers of this study. After being generated, the fine particles with a size smaller than $0.3 \mathrm{~mm}$ were removed for all three opening particle sizes $(8 \mathrm{~mm}, 4 \mathrm{~mm}$, and $2 \mathrm{~mm}$ ) using a sieve size of $0.3 \mathrm{~mm}$.

A sieve analysis was performed for two opening particle size categories of $4 \mathrm{~mm}$ and $2 \mathrm{~mm}$ after conditioning to a moisture content of $12 \%$ (in order to get particles with moisture content of $12 \%$, the particles were conditioned at a temperature of $20{ }^{\circ} \mathrm{C}$ and relative humidity of $65 \%$ to reach an equilibrium moisture of $12 \%$ ). Each particle category was sorted into five sieve groups using four different metal sieves consisting of 3.15, 2, 1 , and $0.5 \mathrm{~mm}$. Then, $100 \mathrm{~g}$ of particles were shaken for a duration of $10 \mathrm{~min}$, and three replications were performed. Finally, the distribution of particle size was calculated as a percentage according to Eq. 3 ,

$$
P_{\mathrm{i}}(\%)=\left(w_{\mathrm{i}} / w\right) \times 100
$$

where $P_{\mathrm{i}}$ is the percentage $(\%)$ of particles on the sieve $i$ compared to the total mass of particles, $w_{\mathrm{i}}$ is the mass ( $\mathrm{g}$ ) of particles on the sieve $i$, and $w$ is the total mass of particles (g).

To determine the slenderness ratio of the particles, 100 particles were randomly selected from each sieve analysis group particle category, and their length and thickness were measured using a digital caliper (Mitutoyo 500-753-20; Mitutoyo Corporation, Kanagawa, Japan). The slenderness ratio of particles was calculated according to Eq. 4,

$$
S=l / d
$$

where $S$ is the slenderness ratio, $l$ is the length of a particle $(\mathrm{mm})$, and $d$ is thickness of a particle (mm).

To manufacture boards, the particle size of $8 \mathrm{~mm}$ was conditioned to a moisture content of $12 \%$, and the particle sizes of $4 \mathrm{~mm}$ and $2 \mathrm{~mm}$ were conditioned to a moisture content of $18 \%$. The particles with a moisture content of $12 \%$ were obtained by conditioning particles at a temperature of $20{ }^{\circ} \mathrm{C}$ and $65 \%$ of relative humidity to reach an equilibrium moisture content of $12 \%$. The particles with a moisture content of $18 \%$ were achieved by conditioning particles at a temperature of $20{ }^{\circ} \mathrm{C}$ and relative humidity of $85 \%$ to reach an equilibrium moisture content of $18 \%$. The two types of three-layered particleboard were labelled type A, consisting of $8 \mathrm{~mm}$ particles for the core layer and 4 $\mathrm{mm}$ for surface layers; type B consisting of $8 \mathrm{~mm}$ particles for the core layer and $2 \mathrm{~mm}$ for the surface layers. The target thickness was $12 \mathrm{~mm}$, and the target density was $0.75 \mathrm{~g} / \mathrm{cm}^{3}$. The boards were manufactured with a mass ratio between surface layers and the core layer of $45 \mathrm{wt} \%$ and $55 \mathrm{wt} \%$ respectively as recommended by Fu (1998). A wooden mold with the dimension of $28 \mathrm{~cm} \times 32 \mathrm{~cm}$ was used for mat forming. Three replications were manufactured for each type of particleboard.

As the adhesive, eMDI I-BOND® PB EM 4352, which was provided by Huntsman Polyurethane (Melbourne, Australia), was applied such that $8 \%$ and $6 \%$ of adhesive were used as a ratio of the oven-dry weight of particles for the surface layers and core layer, respectively. The resin was sprayed using an atomized spray nozzle on the particles in a blender for $5 \mathrm{~min}$ to obtain a homogenized mixture. Two board types were manufactured using a hot press (Carver 3856, Carver Inc., Wabash, IN, USA) with board production parameters displayed in Table 1. 
Table 1. Experiment Design for the Optimization of Opening Face Particle Sizes

\begin{tabular}{|c|c|c|c|c|}
\hline Board Types & $\begin{array}{c}\text { Press } \\
\text { Temperature } \\
\left({ }^{\circ} \mathrm{C}\right)\end{array}$ & $\begin{array}{c}\text { Pressing } \\
\text { Time } \\
(\mathrm{min})\end{array}$ & $\begin{array}{c}\text { Press } \\
\text { Pressure } \\
(\mathrm{MPa})\end{array}$ & $\begin{array}{c}\text { Mat Moisture } \\
\text { Content } \\
(\%)\end{array}$ \\
\hline $\begin{array}{c}\text { A (opening particle size of } 4 \mathrm{~mm} \\
\text { for face layers and 8 } \mathrm{mm} \text { for } \\
\text { core layer) }\end{array}$ & 170 & 3 & 3 & $\begin{array}{c}18 \text { (surface layers) } \\
12 \text { (core layer) }\end{array}$ \\
\hline $\begin{array}{c}\text { B (opening particle size of } 2 \mathrm{~mm} \\
\text { for surface layers and 8 mm for } \\
\text { core layer) }\end{array}$ & 170 & 3 & 3 & $\begin{array}{c}18 \text { (surface layers) } \\
12 \text { (core layer) }\end{array}$ \\
\hline \multicolumn{2}{|c|}{}
\end{tabular}

The press pressure was released slowly over the duration of 1 min after 3 min of pressing time. The slow pressure release was necessary to avoid delamination as a result of the rapid release of steam pressure.

The size of test pieces and methods of testing were compliant with Australian/New Zealand standard AS/NZS 4266.1 (2017). The test specimens were conditioned in a conditioning cabinet at $20^{\circ} \mathrm{C}$ and $65 \% \mathrm{RH}$ to equalize $12 \%$ moisture content. Both MOR and MOE were conducted according to Australian/New Zealand standard AS/NZS 4266.1 (2017) section 7, and the number of test specimens was 9 for each board type. The IB was performed in accordance with AS/NZS 4266.1 (2017) sections 8 and 9, and specimens were tested for each board category. Thickness swelling tests after $2 \mathrm{~h}$ and $24 \mathrm{~h}$ immersion in water on 9 test pieces was conducted for each type of board following AS/NZS 4266.1 (2017) section 10. The density of boards was determined in accordance with AS/NZS 4266.1 (2017) section 6.

The results of this research were analyzed using an analysis of variance (ANOVA) multiple comparison test with a confidence interval of 95\% using Minitab Statistical Software (Minitab LLC, v.19, Minitab Inc., State College, PA, USA).

\section{RESULTS AND DISCUSSION}

\section{Particle Mat Compaction Behavior}

The influences of particle size and moisture content (MC) on compaction behavior of particle mats at room temperature are illustrated in Fig. 4. The data shows different particle sizes have different mat compaction throughout the entire compression process. The mat density at the same level of pressure and moisture content was increased considerably with decreasing particle size. For example, the mat density at a pressure of 5 $\mathrm{N} / \mathrm{mm}^{2}$ and moisture content of $12 \%$ was increased from $0.7 \mathrm{~g} / \mathrm{cm}^{3}$ to $0.8 \mathrm{~g} / \mathrm{cm}^{3}$ with decreasing opening particle size from $8 \mathrm{~mm}$ to $2 \mathrm{~mm}$, respectively.

The finding of increasing compression stiffness at room temperature of the mat with increasing particle size can be explained as particles with large size are able to bridge the gaps and contribute to compression resistance as a consequence of bending. Therefore, compression stiffness of mats containing larger particle size is higher than that of mats with smaller particle size.

Furthermore, it can also be seen from Fig. 4 that the moisture content of particles had an impact on the compaction behavior of the particle mat. The density of the particle mat increased with increasing the moisture content of the particles. The density of mats with a particle size of $8 \mathrm{~mm}$ increased from $0.7 \mathrm{~g} / \mathrm{cm}^{3}$ to $0.83 \mathrm{~g} / \mathrm{cm}^{3}$ at a pressure of 5 $\mathrm{N} / \mathrm{mm}^{2}$ with the moisture content of particles increasing from $12 \%$ to $30 \%$. 

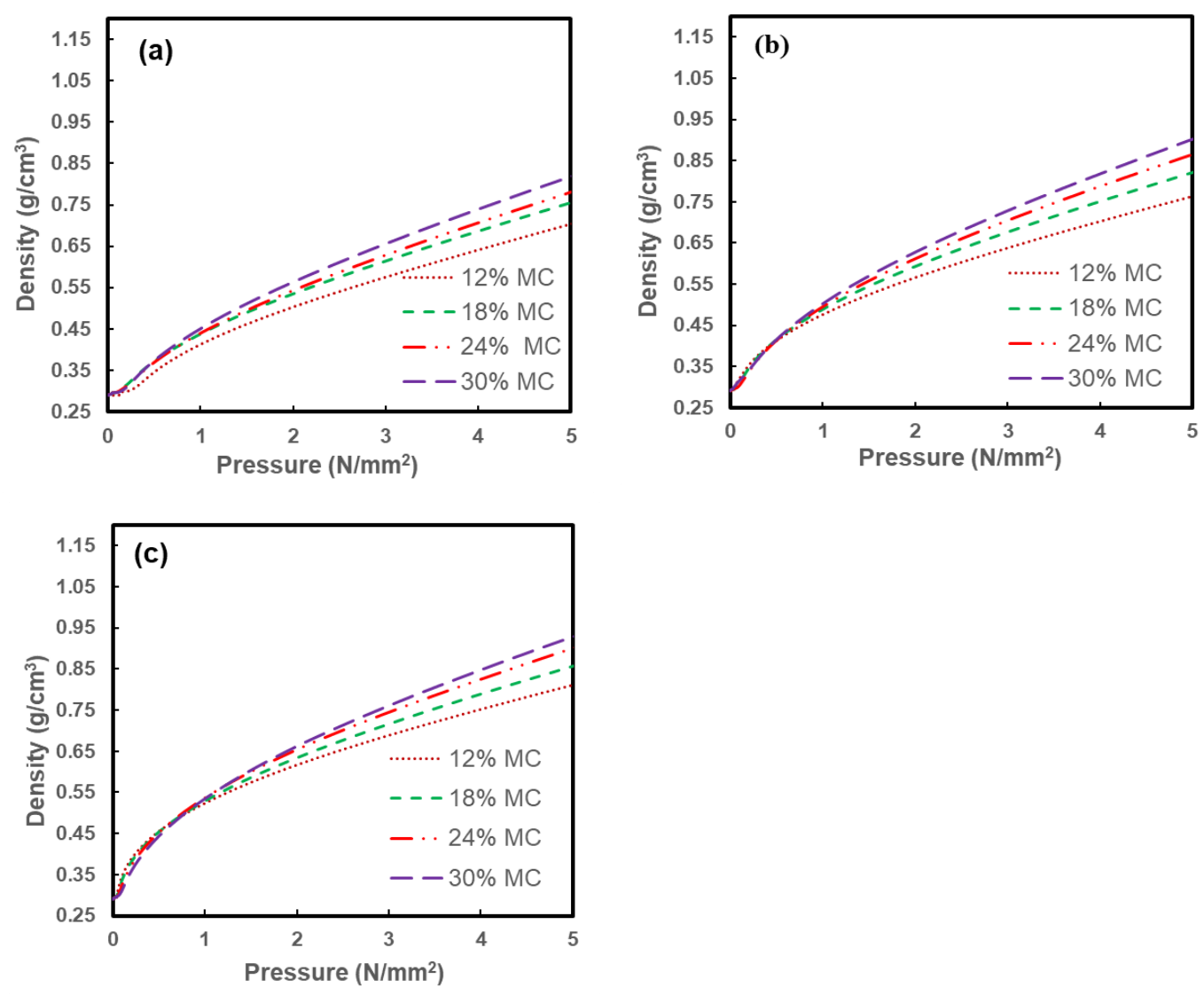

Fig. 4. Compaction behavior of the particle mat at room temperature at different $M C$ of the mat with $8 \mathrm{~mm}$ particle size (a), mat with $4 \mathrm{~mm}$ particle size (b), and mat with $2 \mathrm{~mm}$ particle size (c).

The density values of mats with particle sizes of $4 \mathrm{~mm}$ and $2 \mathrm{~mm}$ increased from $0.77 \mathrm{~g} / \mathrm{cm}^{3}$ to $0.9 \mathrm{~g} / \mathrm{cm}^{3}$ and $0.8 \mathrm{~g} / \mathrm{cm}^{3}$ to $0.92 \mathrm{~g} / \mathrm{cm}^{3}$, respectively. This phenomenon can be explained by changes in the proportions of bound water in the wood. The average moisture content at the fiber saturation point (FSP) is approximately $30 \%$ (Glass and Zenlinka 2010). When the moisture content is below the FSP, the change in moisture content has an effect on wood strength. Increasing the amount of bound water leads to reducing hydrogen bonding between the organic polymers of the cell wall (Glass and Zenlinka 2010), which reduces the strength of wood.

The density of particle mats at temperatures of 50 and $75^{\circ} \mathrm{C}$ and different moisture contents (MC) is shown in Fig. 5. Results revealed that the mat density of all particle sizes at all moisture contents increased considerably compared to those values at room temperature with increasing temperature of particle mats to 50 and $75^{\circ} \mathrm{C}$. For instance, the density of mat with a particles size of $8 \mathrm{~mm}$ at a moisture content of $12 \%$ and pressure of $5 \mathrm{~N} / \mathrm{mm}^{2}$ was increased from $0.7 \mathrm{~g} / \mathrm{cm}^{3}$ at room temperature to $0.8 \mathrm{~g} / \mathrm{cm}^{3}$ at a temperature of $75^{\circ} \mathrm{C}$. Similarly, under the same conditions, the density of mats containing particle sizes of $4 \mathrm{~mm}$ and $2 \mathrm{~mm}$ were increased from 0.77 to $0.94 \mathrm{~g} / \mathrm{cm}^{3}$ and 0.83 to $1.0 \mathrm{~g} / \mathrm{cm}^{3}$, respectively. This indicates that increasing temperature resulted in decreasing compression stiffness of the particle mat. The explanation for this is that increased temperature creates an increase in the plasticity of lignin and an increase in spatial size. This decreases intermolecular contact leading to a loss in wood strength (Winandy and Rowell 2005). 

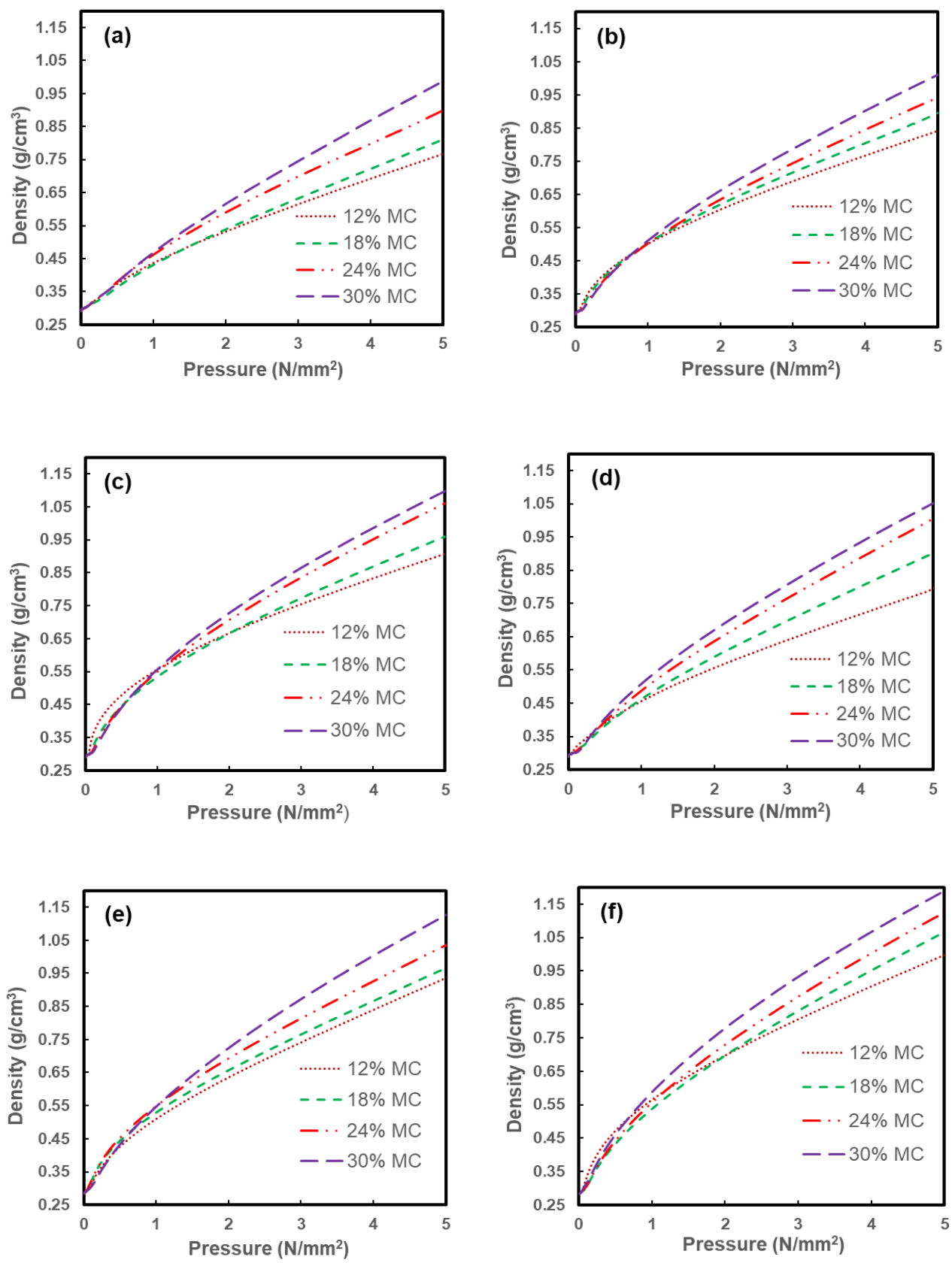

Fig. 5. Compaction behavior at different MCs of the mat with $8 \mathrm{~mm}$ particle size at $50^{\circ} \mathrm{C}(\mathrm{a})$, mat with $4 \mathrm{~mm}$ particle size at $50^{\circ} \mathrm{C}$ (b), mat with $2 \mathrm{~mm}$ particle size at $50^{\circ} \mathrm{C}$ (c), mat with $8 \mathrm{~mm}$ particle size at $75^{\circ} \mathrm{C}(\mathrm{d})$, mat with $4 \mathrm{~mm}$ particle size at $75^{\circ} \mathrm{C}(\mathrm{e})$, and mat with $2 \mathrm{~mm}$ particle size at $75^{\circ} \mathrm{C}(\mathrm{f})$.

Furthermore, hemicellulose is amorphous and essentially thermoplastic (Back and Salmén 1982). This means that hemicellulose become more plasticized with the increase in temperature, which also contributes to wood strength reduction.

It can be seen from Fig. 6 that when the particle mat temperature was increased to $100{ }^{\circ} \mathrm{C}$, the mat density for all particle sizes and moisture contents decreased compared to a temperature of $75^{\circ} \mathrm{C}$ (Figs. 5d, through 5f). For example, the density of the mat with a particle size of $2 \mathrm{~mm}$ at a pressure of $5 \mathrm{~N} / \mathrm{mm}^{2}$ and moisture content of $12 \%$ decreased from 1.0 to $0.9 \mathrm{~g} / \mathrm{cm}^{3}$ with increasing temperature from 75 to $100{ }^{\circ} \mathrm{C}$. This is not in line 
with the theory mentioned above that an increase in temperature results in increasing mat density (see Fig. 5 for when temperature increased from room temperature to $50^{\circ} \mathrm{C}$ and then $75^{\circ} \mathrm{C}$ ). The potential reason for this is that at a temperature of $100^{\circ} \mathrm{C}$, water is starting to evaporate and generate water vapor. During pressing, the water vapor can become trapped, and the resulting steam pressure opposes the closing pressure of the press. This is in line with the results indicated in Fig. 9, which indicate that higher particle mat moisture content led to higher plateau temperature and plateau time. It is well known that higher plateau temperature leads to higher steam pressure and longer plateau time resulting in a longer duration of keeping that steam pressure. Furthermore, when pressing pressure reaches $5 \mathrm{~N} / \mathrm{mm}^{2}$, the compression process is stopped but the water vapor still does not escape from the mat.
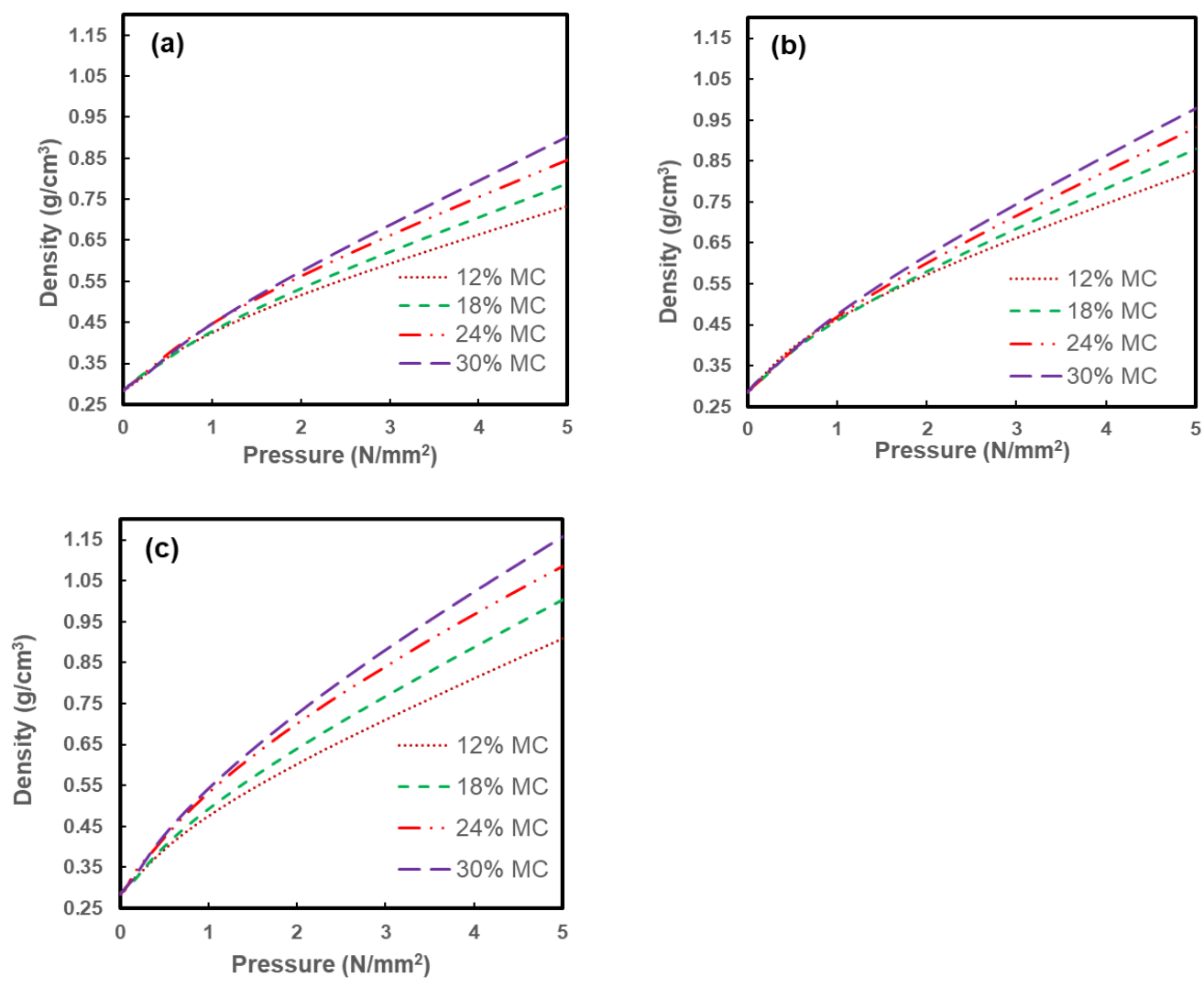

Fig. 6. Compaction behavior of the particle mat at $100^{\circ} \mathrm{C}$ and different $\mathrm{MC}$ of mat with $8 \mathrm{~mm}$ particle size (a), mat with $4 \mathrm{~mm}$ particle size (b), and mat with $2 \mathrm{~mm}$ particle size (c).

Figure 7 shows the results of particle mat densities when the temperature of the mats was increased from 125 to $170^{\circ} \mathrm{C}$. This indicates that the mats' density decreased with increasing moisture content when the temperature of the mats reached $125^{\circ} \mathrm{C}$ and onward. This is the opposite trend compared to when temperature increased from room temperature to $100{ }^{\circ} \mathrm{C}$. The reason for this is most likely that at an elevated temperature from $125^{\circ} \mathrm{C}$ and above, a higher moisture content mat will generate higher vapor pressure that opposes the pressing pressure during the molding process. This is explained more clearly in the next section (temperature behavior inside the mat of the boards). 

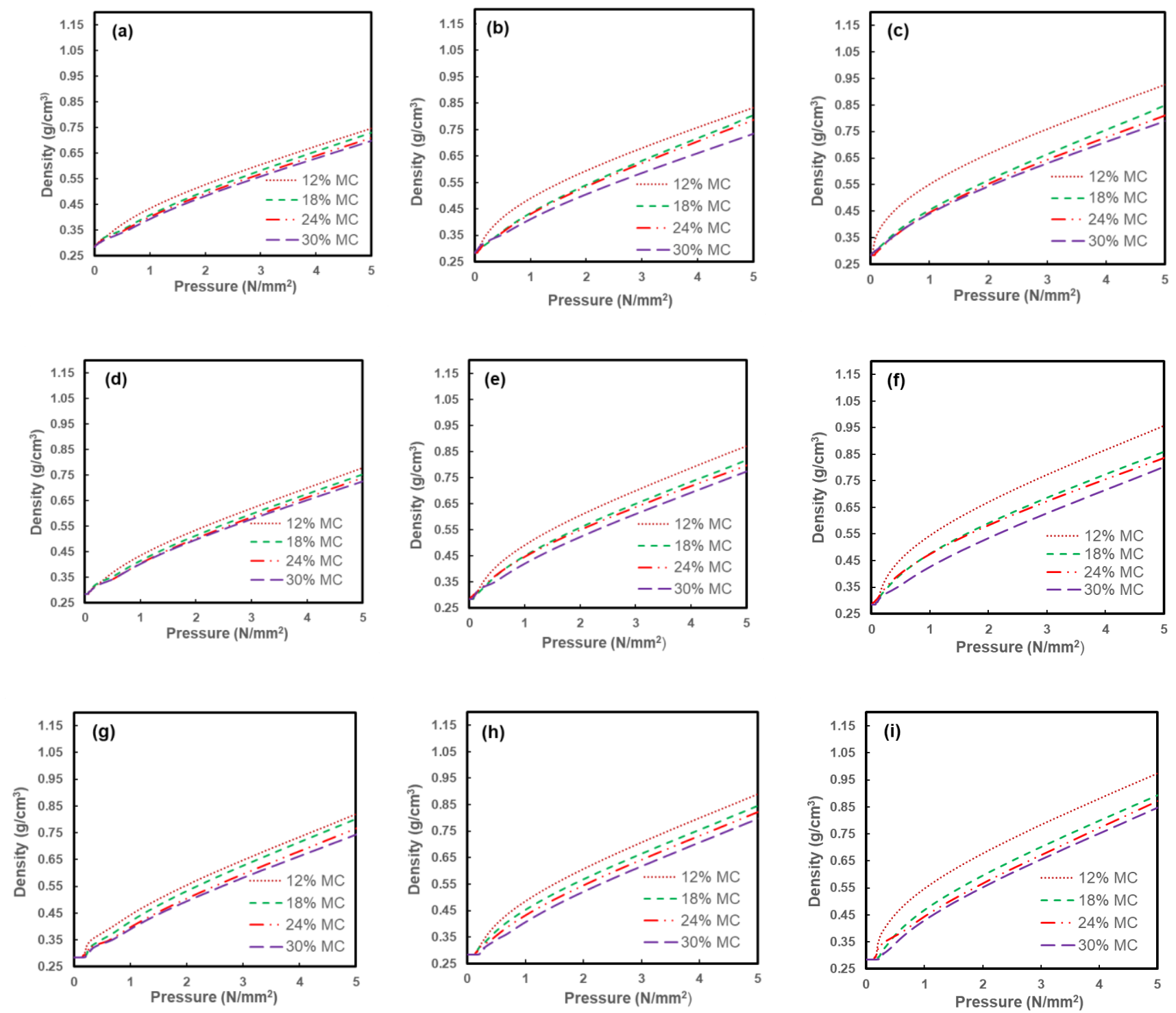

Fig. 7. Compaction behavior of the particle mat at different $\mathrm{MC}$ of mat with $8 \mathrm{~mm}$ particle size at $125^{\circ} \mathrm{C} \mathrm{(a),} 4 \mathrm{~mm}$ particle size at $125^{\circ} \mathrm{C}$ (b), $2 \mathrm{~mm}$ particle size at $125^{\circ} \mathrm{C}$ (c), $8 \mathrm{~mm}$ particle size at $150^{\circ} \mathrm{C}(\mathrm{d}), 4 \mathrm{~mm}$ particle size at $150^{\circ} \mathrm{C}(\mathrm{e}), 2 \mathrm{~mm}$ particle size at $150^{\circ} \mathrm{C}$ (f), $8 \mathrm{~mm}$ particle size at $170^{\circ} \mathrm{C}(\mathrm{g}), 4 \mathrm{~mm}$ particle size at $170^{\circ} \mathrm{C}(\mathrm{h})$, and $2 \mathrm{~mm}$ particle size at $170^{\circ} \mathrm{C}(\mathrm{i})$.

The findings from particle mat compaction behavior indicate that to develop the best density profile in the thickness direction, the coarse particles with lower moisture content and fine particles with higher moisture content should be applied for the core layer and surface layers, respectively. The findings also emphasize that another factor that contributes to the best density profile development is a rapid closing rate, which should also be applied to ensure that at the moment the top plate of the hot press touches the stop bar, the temperature in the core of the mat is still around room temperature.

\section{Temperature Behavior Inside the Boards}

The results of surface temperature change during hot-pressing of homogenous boards with various particle sizes and moisture contents are shown in Fig. 8. This indicates 
that the temperature change was almost the same for all particle sizes and moisture contents. This means particle size and moisture content do not have an effect on the surface temperature profile as hot-pressing progresses. The reason for this is that the surface of the board is directly in contact with the aluminium sheet, so heat is rapidly transferred from the hot plate through the aluminium sheet to the surface of the board.
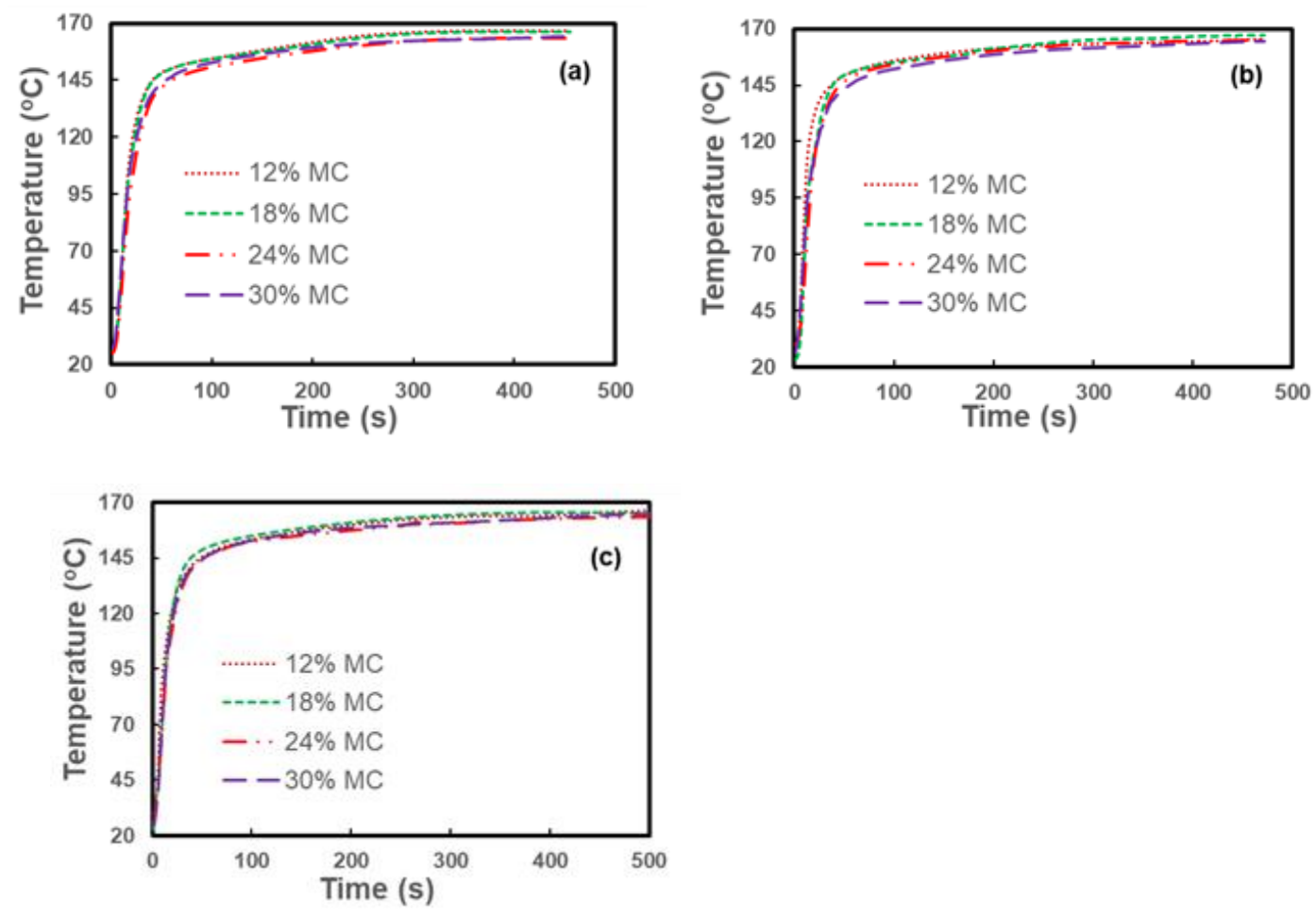

Fig. 8. The surface temperature profile as influenced by different $M C$ of the mat with $8 \mathrm{~mm}$ particle size (a), mat with $4 \mathrm{~mm}$ particle size (b), and mat with $2 \mathrm{~mm}$ particle size (c).

The results of the core temperature behavior of boards with various moisture contents and particle sizes are provided in Fig. 9. The results revealed that the core temperature behavior of boards with different particle sizes in general presented a similar trend at the same moisture content level. However, the core temperature profile of boards with mat moisture contents of $24 \%$ and $30 \%$ was different from boards with mat moisture contents of $12 \%$ and $18 \%$.

The maximum core temperature reached in the early stage of pressing was approximately 117 and $125^{\circ} \mathrm{C}$ in the short term for mat moisture contents of $24 \%$ and $30 \%$, respectively, and then after reaching their peak core temperatures decreased. The reason for this is likely that the higher mat moisture content generates more steam that leads to an increase in the internal steam pressure (Cai et al. 2006). It is well known that temperature corresponds to an equilibrium with steam pressure, so the higher the steam pressure, the higher the temperature and vice versa. In contrast, higher steam pressure that forces the moisture to flow along the centerline to the mat edges more quickly may result in a decrease in core steam pressure that in turn reduces the core temperature.

The finding that the core temperature of boards with a moisture content of $24 \%$ and $30 \%$ reached higher maximum temperatures, compared to mats of lower moisture content, due to high steam pressure generated inside the mats, is in line with the previous findings in this paper that at an elevated temperature from $125^{\circ} \mathrm{C}$ and above the mats' density 
decreased with increasing moisture content. The high steam pressure created inside the mat has the potential for boards to blow and delaminate when the press pressure is released. It is for this reason that a mat moisture content higher than $20 \%$ has not been recommended during production.
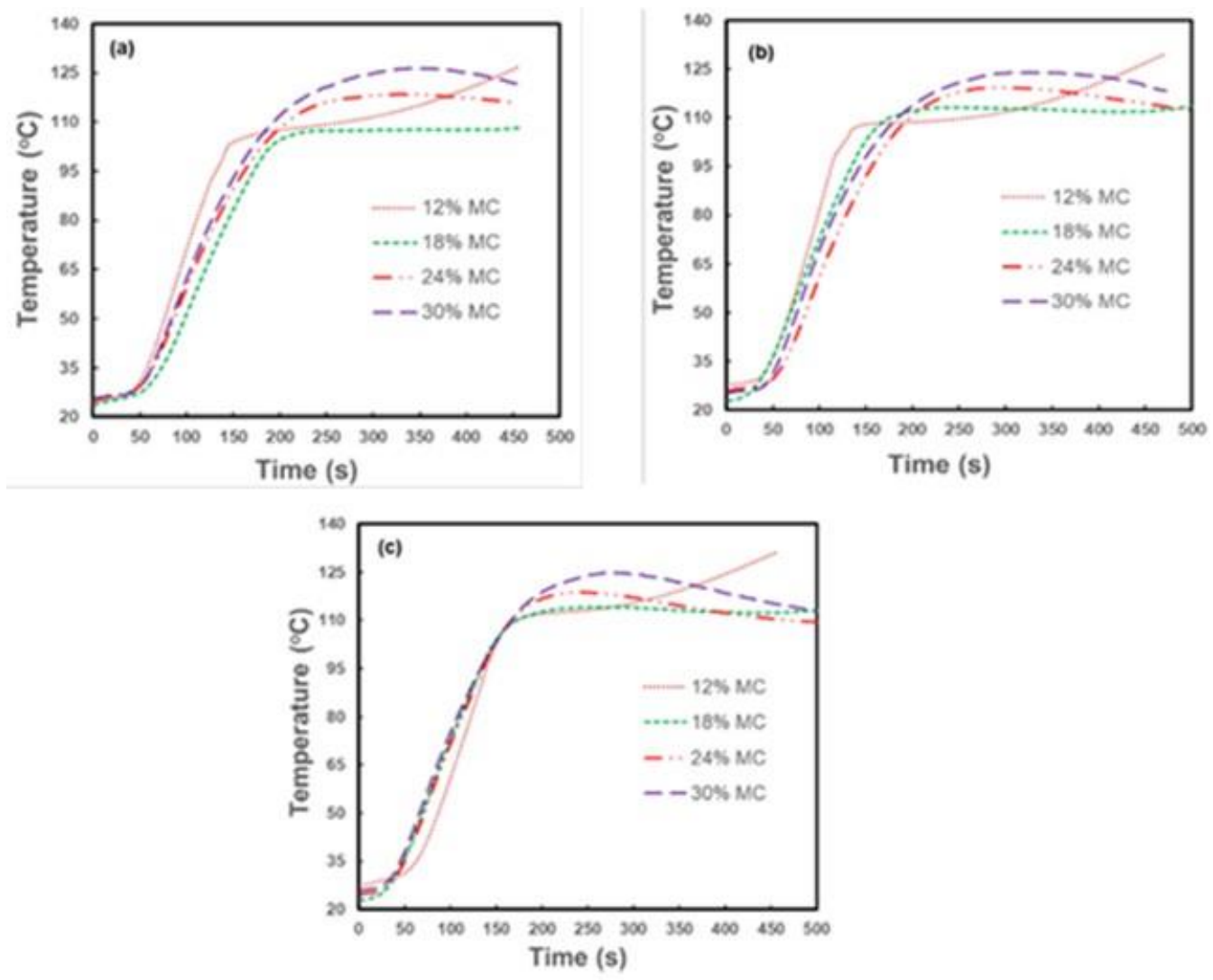

Fig. 9. The core temperature profile as influenced by different $M C$ of the mat with $8 \mathrm{~mm}$ particle size (a), mat with $4 \mathrm{~mm}$ particle size (b), and mat with $2 \mathrm{~mm}$ particle size (c).

It can be also seen from Fig. 9, for the mats with moisture contents of $12 \%$ and $18 \%$, that the maximum core temperature in the early stage of pressing reached approximately $110^{\circ} \mathrm{C}$ and kept constant for the period of time, called the plateau period; however, the plateau period was hugely different between mat particle sizes and moisture contents. The lowest and highest plateau temperatures were seen in the mat with a particle size of $8 \mathrm{~mm}$ and $2 \mathrm{~mm}$, respectively, for both mat moisture contents of $12 \%$ and $18 \%$. This means that the particle size of mats had an influence on plateau temperature, and this temperature increased with decreasing particle size at the same moisture content level.

The plateau period increased noticeably when mat moisture content increased from $12 \%$ to $18 \%$ for all types of boards. The reason for this is a result of the amount of water present. Mats with a higher moisture content need more energy for water to vaporize. Therefore, when the same amount of heat was provided to mats, the mat with higher moisture content will need more time for vaporization to occur (Rofii et al. 2014).

An observable difference between the plateau time of boards with coarse particles $(8 \mathrm{~mm})$ and boards with fine particles $(4 \mathrm{~mm}$ and $2 \mathrm{~mm}$ ) was noted. For example, the plateau time of boards with a particle size of $8 \mathrm{~mm}$ was approximately $230 \mathrm{~s}$ at a mat moisture content of $18 \%$ compared to approximately $310 \mathrm{~s}$ for boards with a particle size 
of $2 \mathrm{~mm}$ at the same moisture content. This is because a more porous structure of mats with coarse particles exist compared to that of mats with fine particles. The porosity is related to water vapor permeability, and the greater the permeability, the easier it is for water vapor to escape from the mat during hot pressing (Dai et al. 2004; Kamke 2004). This also explains why the plateau temperature of boards with coarse particles is lower than that of boards with fine particles at the same moisture content.

The plateau time at the core of mats with coarse particles was lower than that of mats with fine particles, at the same moisture content level. This revealed another benefit of making particleboard, where combining fine particles in the surface layers and coarse particles in the core layer, apart from creating a board with higher density in the surface and lower density in the core, is that it also contributes to prevent board delamination as a consequent of shortening the water vaporization stage (water vapor escapes faster). This combination could be better in cases where the higher moisture in the surface layers and lower moisture in core layer are applied because at a given average density of a board, the increase in surface density results in decreasing density in the core leading to a more porous structure in the core that lets water vapor escape more easily.

To select the best combination of moisture content levels between the surface and core layers, the measurements of temperature behavior in the mat of boards at various levels of moisture content between surface and core layers, were conducted, and the results are presented in Fig. 10. The three-layered boards with the same moisture content in the core layer (12\%), but different moisture content levels in the surface layer $(18 \%, 24 \%$, and $30 \%$ ) were investigated. As a result of the previous section presented in this paper, the temperature behavior of $2 \mathrm{~mm}$ and $4 \mathrm{~mm}$ particles sizes were not significantly different. Therefore, the boards were constructed using $2 \mathrm{~mm}$ opening particle sizes for the surface layers and $8 \mathrm{~mm}$ opening particles sizes for the core.
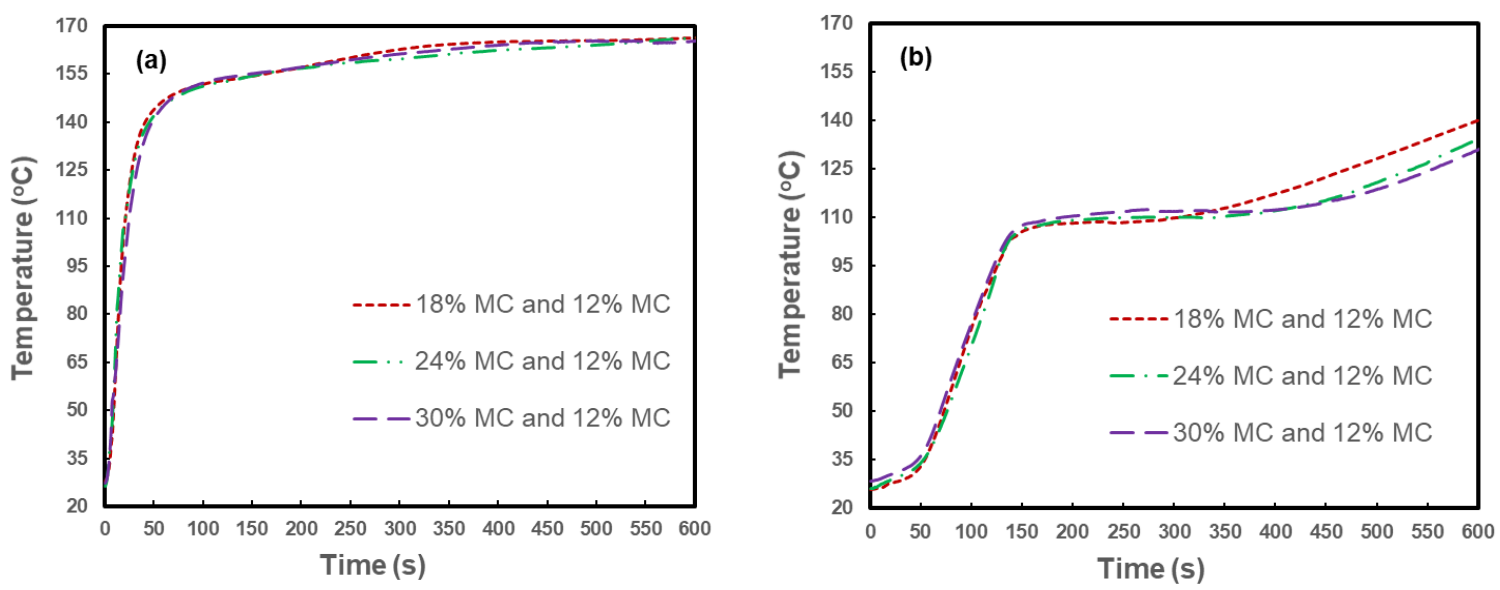

Fig. 10. Temperature profile at surface (a), and core (b) as influenced by non-uniform mat moisture content of three-layered boards.

Figure 10a shows that boards with different surface moisture contents had almost the same temperature profile at the surface. This further confirms that mat moisture content did not affect the surface temperature behavior. However, the temperature behavior in the core of boards was different, as shown in Fig. 10b. More detail on plateau temperatures and times can be seen in Table 2 . 
Table 2. Plateau Temperature and Time of the Core Layer at Various Mat Surface Moisture Content Levels

\begin{tabular}{|c|c|c|}
\hline Board Types & $\begin{array}{c}\text { Plateau Temperature } \\
\left({ }^{\circ} \mathrm{C}\right)\end{array}$ & $\begin{array}{c}\text { Plateau Time } \\
(\mathrm{s})\end{array}$ \\
\hline Surface MC 18\% and Core MC 12\% & 108 & 120 \\
\hline Surface MC 24\% and Core MC 12\% & 110 & 170 \\
\hline Surface MC 30\% and Core MC 12\% & 112 & 200 \\
\hline
\end{tabular}

The data in Table 2 reveal that the plateau temperature and time increased with increasing surface mat moisture content. This is because, during hot-pressing, the moisture at the mat surface vaporizes and produces vapor pressure that travels to the core leading to increased moisture in the core. Consequently, mats with a higher surface moisture content will force more moisture to come to the core during hot-pressing.

It can be observed from Fig. 10b that the core temperature increase from room temperature to $100{ }^{\circ} \mathrm{C}$ for all three different moisture content combinations was almost at the same rate, and they also all had a similar plateau temperature of around $110{ }^{\circ} \mathrm{C}$. Consequently, it is believed that the curing rate of resin was also almost the same for each combination. Overall, the resin curing in the core (centerline) of boards was not fully completed during the designated cycle of hot-pressing; hence, residual internal steam pressure could sometimes exceed the IB strength at the moment of releasing the press pressure, which leads to board delamination. Therefore, less residual internal steam pressure can reduce the chances of board delamination. The boards with a mat moisture content of $18 \%$ and $12 \%$ had a plateau time of $120 \mathrm{~s}$, which is much lower than those of boards with mat moisture content of $24 \%$ and $12 \%$ and $30 \%$ and $12 \%$, (170 s and $200 \mathrm{~s}$, respectively). This means that boards with mat moisture content of $18 \%$ and $12 \%$ will have less residual internal steam pressure compared to those of boards with mat moisture content of $24 \%$ and $12 \%$ and $30 \%$ and $12 \%$ when releasing the press pressure. Cai et al. (2006) recommended that mat moisture contents between $10.8 \%$ and $18.5 \%$ can be applied when using isocyanate resins. Moreover, Frazier (2003) suggested that mat moisture content levels ranging from $12 \%$ to $20 \%$ will yield acceptable board performance with pMDI resins. In this study, emulsifiable polymeric isocyanate (eMDI) was used. Therefore, a mat moisture content of $18 \%$ in surface layers and a mat moisture content of $12 \%$ in the core layer (this is equal to an average mat moisture content of around 15\%) are highly recommended for selection.

\section{Optimization of Opening Particle Size for Surface Layers}

The average distribution of particles by weight and standard deviation of the two different opening particle size categories $(4 \mathrm{~mm}$ and $2 \mathrm{~mm}$ ) are shown in Table 3 .

Table 3. Average Weight Distribution of Two Particle Size Categories

\begin{tabular}{|c|c|c|c|c|c|}
\hline \multirow[b]{2}{*}{$\begin{array}{c}\text { Particle } \\
\text { Categories }\end{array}$} & \multicolumn{5}{|c|}{ Average Proportion (\%) } \\
\hline & $\begin{array}{c}\text { Particles on } \\
3.15 \mathrm{~mm} \\
\text { Sieve }\end{array}$ & $\begin{array}{c}\text { Particles } \\
\text { Between } \\
3.15 \text { and } 2.0 \\
\text { mm Sieves }\end{array}$ & $\begin{array}{c}\text { Particles } \\
\text { Between } 2.0 \\
\text { and } 1.0 \mathrm{~mm} \\
\text { Sieves }\end{array}$ & $\begin{array}{c}\text { Particles } \\
\text { Between } 1.0 \\
\text { and } 0.5 \mathrm{~mm} \\
\text { Sieves }\end{array}$ & $\begin{array}{c}\text { Particle } \\
\text { Passed } \\
\text { Through } 0.5 \\
\text { mm Sieves }\end{array}$ \\
\hline $4 \mathrm{~mm}$ & 0.00 & $1.85(0.07)$ & $41.99(0.79)$ & $46.65(0.94)$ & $9.51(0.19)$ \\
\hline $2 \mathrm{~mm}$ & 0.00 & 0.00 & $2.33(0.02)$ & $67.23(1.85)$ & $30.44(1.75)$ \\
\hline
\end{tabular}

Nguyen et al. (2021). "Cotton stalk particleboard," BioResources 16(2), 4149-4170. 
The average slenderness ratio measured from 100 particles of each sieve analysis group is shown in Table 4. There were noticeably different slenderness ratio values of particles between sieve analysis groups. The highest particle slenderness ratio (15.19) was found in the sieve analysis group between sieve sizes of $1.0 \mathrm{~mm}$ and $0.5 \mathrm{~mm}$. This figure was almost 2.5 times higher than the smallest one (6.16), which was recorded in the sieve analysis group between sieve sizes of $3.15 \mathrm{~mm}$ and $2.0 \mathrm{~mm}$.

Based on the average weight distribution in each opening particle size category (Table 3) and average slenderness ratio of each sieve analysis category of particles (Table 4), the average slenderness ratio of each opening particle size category was calculated, as shown in Table 5.

Table 4. Average Slenderness Ratio of Sieve Analysis Groups

\begin{tabular}{|c|c|c|c|c|}
\hline $\begin{array}{c}\text { Analysis } \\
\text { Sieve Groups }\end{array}$ & $\begin{array}{c}\text { Particles } \\
\text { Between 3.15 } \\
\text { and } 2.0 \mathrm{~mm} \\
\text { Sieves }\end{array}$ & $\begin{array}{c}\text { Particles } \\
\text { Between 2.0 } \\
\text { and } 1.0 \mathrm{~mm} \\
\text { Sieves }\end{array}$ & $\begin{array}{c}\text { Particles Between } \\
1.0 \text { and } 0.5 \mathrm{~mm} \\
\text { Sieves }\end{array}$ & $\begin{array}{c}\text { Particles Passed } \\
\text { Through } 0.5 \mathrm{~mm} \\
\text { Sieves }\end{array}$ \\
\hline $\begin{array}{c}\text { Slenderness } \\
\text { Ratio }\end{array}$ & 6.16 & 12.4 & 15.19 & 8.18 \\
\hline
\end{tabular}

Table 5. Average Slenderness Ratio of Two Opening Particle Size Categories

\begin{tabular}{|c|c|c|}
\hline Particle Categories & Opening Size of $4 \mathrm{~mm}$ & Opening Size of $2 \mathrm{~mm}$ \\
\hline Slenderness Ratio & 13.18 & 12.99 \\
\hline
\end{tabular}

It can be seen from Table 5 that the opening particle sizes of $4 \mathrm{~mm}$ and $2 \mathrm{~mm}$ had almost the same slenderness ratio

\section{Mechanical and Physical Properties of Two Particleboard Types}

Two three-layered types of boards, with core particle size of $8 \mathrm{~mm}$ and surface particle sizes of $4 \mathrm{~mm}$ and $2 \mathrm{~mm}$ (type A $4 \mathrm{~mm}$ and $8 \mathrm{~mm}$, type B $2 \mathrm{~mm}$ and $8 \mathrm{~mm}$ ) were manufactured to optimize the particle size for the surface layers. It is widely known that one of the important factors that influences mechanical properties of particleboard is density. The result from the analysis of the variance of density among two types of boards is presented in Table 6, which revealed that the density differences between the two types of manufactured boards were insignificant. Consequently, its influence on boards' performance was not taken into consideration.

Table 6. Density ANOVA Multiple Comparison Based on Tukey's Significant Different Test

\begin{tabular}{|c|c|c|}
\hline \multirow{2}{*}{ Board Types } & $\begin{array}{c}\text { Average Density } \\
\left(\mathrm{g} / \mathrm{cm}^{3}\right)\end{array}$ & \begin{tabular}{c} 
Groups Subset for $\alpha=0.05$ \\
\cline { 2 - 3 }
\end{tabular} \\
\hline A $(4 \mathrm{~mm}$ and $8 \mathrm{~mm})$ & $0.740(0.029)$ & $\mathrm{x}$ \\
\hline B $(2 \mathrm{~mm}$ and $8 \mathrm{~mm})$ & $0.751(0.035)$ & \\
\hline \multicolumn{2}{|c|}{ Note: Standard deviation is presented in parentheses } \\
\hline
\end{tabular}

Figure 11 demonstrates the average values and distribution of MOR and MOE of board type A and type B with different opening surface particle sizes of $4 \mathrm{~mm}$ and $2 \mathrm{~mm}$, 
respectively. The values of both MOR and MOE increased with decreasing surface particle size from $4 \mathrm{~mm}$ in board type A to $2 \mathrm{~mm}$ in board B although opening particle sizes of 4 $\mathrm{mm}$ and $2 \mathrm{~mm}$ had almost the same slenderness ratio as shown in Table 5. This is because the mat density of $2 \mathrm{~mm}$ particle size was much higher than that of $4 \mathrm{~mm}$ particle size under the same mat moisture content and hot-press parameters as previously discussed. The surface density had a significant influence on the MOR and MOE values of a particleboard, as the bending stresses were higher at the surface. Results obtained from ANOVA of MOR and MOE between boards type A (4 $\mathrm{mm}$ and $8 \mathrm{~mm})$ and type $\mathrm{B}(2 \mathrm{~mm}$ and $8 \mathrm{~mm})$ are illustrated in Table 7. The results revealed that the MOR and MOE values of board type B were significantly higher than those of board type A.

It can also be seen from Fig. 11 that the average values of modulus of rupture and modulus of elasticity of both board type A and board type B met the requirements of standard and moisture resistant particleboards according to the Australian/New Zealand standard AS/NZS 1859.1 (2017), part 1: Particleboard.
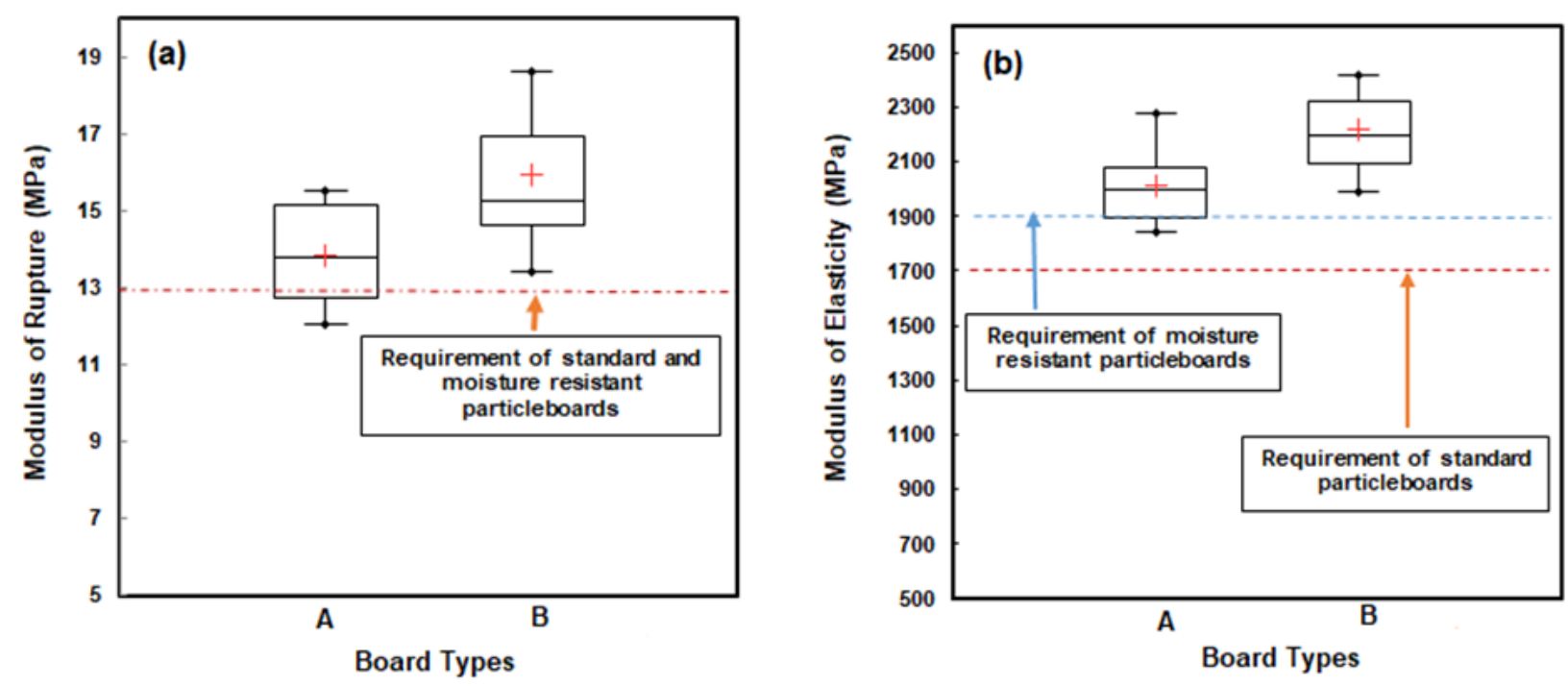

Fig. 11. Effect of opening particle size on (a) MOR and (b) MOE.

Table 7. MOR and MOE ANOVA Multiple Comparison Based on Tukey's Significant Difference Test

\begin{tabular}{|c|c|c|c|c|c|c|c|}
\hline \multirow{2}{*}{$\begin{array}{l}\text { Board } \\
\text { Types }\end{array}$} & \multirow{2}{*}{$\begin{array}{c}\text { Average of MOR } \\
(\mathrm{MPa})\end{array}$} & \multicolumn{2}{|c|}{$\begin{array}{c}\text { Groups Subset } \\
\text { for } \alpha=0.05\end{array}$} & \multirow{2}{*}{$\begin{array}{c}\text { Board } \\
\text { Types }\end{array}$} & \multicolumn{2}{|c|}{$\begin{array}{c}\text { Average of MOE } \\
(\mathrm{MPa})\end{array}$} & \multicolumn{2}{c|}{$\begin{array}{c}\text { Groups Subset } \\
\text { for } \alpha=0.05\end{array}$} \\
\cline { 3 - 4 } & & 1 & 2 & & & 1 & 2 \\
\hline $\mathrm{B}$ & $15.93(1.86)$ & $\mathrm{x}$ & & $\mathrm{B}$ & $2215.9(141.7)$ & $\mathrm{x}$ & \\
\hline $\mathrm{A}$ & $13.87(1.35)$ & & $\mathrm{x}$ & $\mathrm{A}$ & $2010.7(149.2)$ & & $\mathrm{x}$ \\
\hline
\end{tabular}




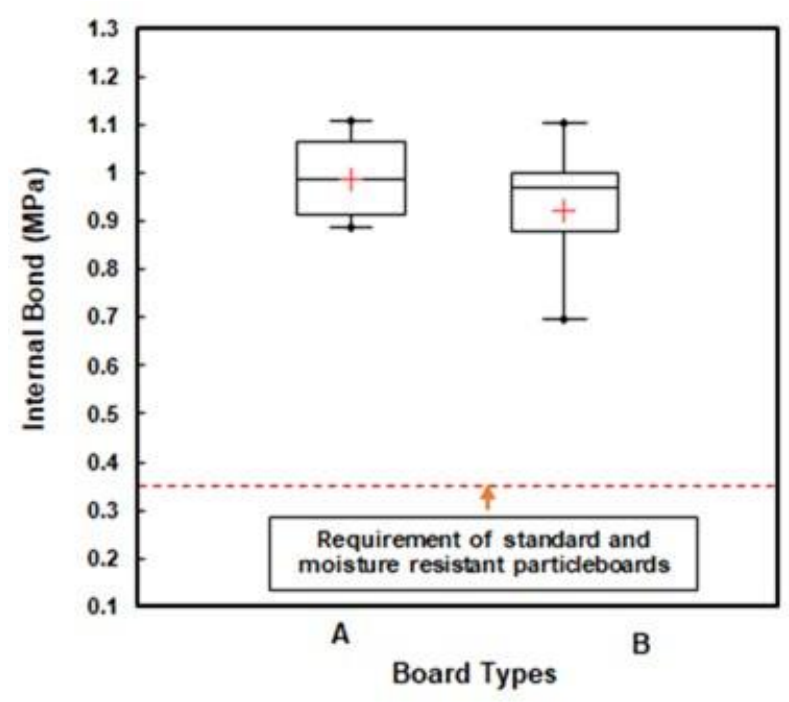

Fig. 12. Effect of surface particle size on IB strength.

The effect of surface particle size on the IB strength is presented in Fig. 12. Results indicate that in contrast to MOR and MOE, the IB value of board type A (4 mm and $8 \mathrm{~mm}$ ) was higher than that of board type B $(2 \mathrm{~mm}$ and $8 \mathrm{~mm})$, meaning that IB decreased with decreasing surface particle size. This is because, as both board types have the same average density and board type B has a higher surface density than board type A, board type B therefore has a lower core density. A lower core density will comparatively have more void space and less bonding sites contributing to the lower IB result of board type B.

Table 8. IB ANOVA Multiple Comparison Based on Tukey's Significant Different Test

\begin{tabular}{|c|c|c|c|}
\hline \multirow{2}{*}{ Board Types } & $\begin{array}{c}\text { Average of IB } \\
(\mathrm{MPa})\end{array}$ & \multicolumn{2}{|c|}{ Groups Subset for $\alpha=0.05$} \\
\cline { 2 - 4 } & $0.98(0.09)$ & $\mathrm{x}$ & \\
\hline $\mathrm{A}$ & $0.92(0.13)$ & $\mathrm{x}$ & \\
\hline $\mathrm{B}$ & \multicolumn{2}{|c|}{} \\
\hline \multicolumn{2}{|c|}{ Note: Standard deviation is presented in parentheses }
\end{tabular}

The results of ANOVA of IB in Table 8 indicate that the IB value of board type A was insignificantly higher than that of board type B. Furthermore, the average IB strength of both board types was much higher than the requirements for standard and moisture resistant particleboards according to the Australian/New Zealand standard AS/NZS 1859.1 (2017), part 1: Particleboard (Fig. 12). This means that the resin content in the core layer could be reduced as a cost saving mechanism. 

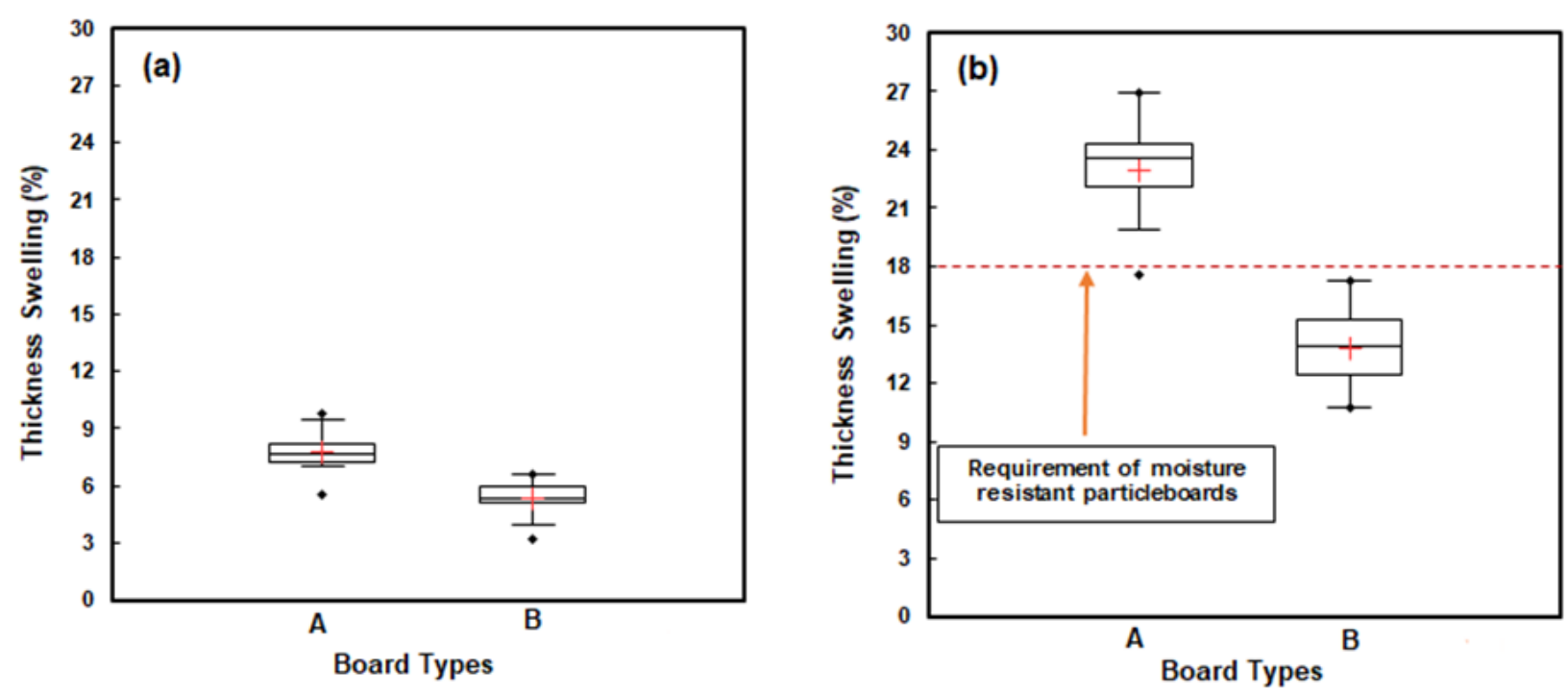

Fig. 13. Effect of surface particle size on TS (thickness swelling) after (a) $2 \mathrm{~h}$ and (b) $24 \mathrm{~h}$

Figure 13 demonstrates the maximum, minimum, and average values of the effect of surface particle size on the TS after $2 \mathrm{~h}$ and $24 \mathrm{~h}$ immersion in water. The TS decreased with decreasing surface particle size from $4 \mathrm{~mm}$ (board type A) to $2 \mathrm{~mm}$ (board type B) after $2 \mathrm{~h}$ as well as $24 \mathrm{~h}$ immersion in water. This is because the surface density of board type A was lower than that of board type B, leading to larger voids in surface layers of board type A compared to those of board type B. The presence of lower density areas and larger voids in the boards results in water penetration and easy access to interior board layers (Houts et al. 2004). These voids also provide space for free water, which eventually results in high water uptake and board swell.

Table 9. TS $2 \mathrm{~h}$ and TS $24 \mathrm{~h}$ ANOVA Multiple Comparison Based on Tukey's Significant Difference Test

\begin{tabular}{|c|c|c|c|c|c|c|c|}
\hline \multirow{2}{*}{$\begin{array}{l}\text { Board } \\
\text { Types }\end{array}$} & $\begin{array}{c}\text { Average of TS } 2 \mathrm{~h} \\
(\%)\end{array}$ & \multicolumn{2}{|c|}{$\begin{array}{c}\text { Groups Subset } \\
\text { for } \alpha=0.05\end{array}$} & \multirow{2}{*}{$\begin{array}{c}\text { Board } \\
\text { Types }\end{array}$} & $\begin{array}{c}\text { Average of TS } 24 \mathrm{~h} \\
(\%)\end{array}$ & $\begin{array}{c}\text { Groups Subset } \\
\text { for } \alpha=0.05\end{array}$ \\
\cline { 3 - 4 } & & 1 & 2 & & & 1 & 2 \\
\hline A & $7.76(1.28)$ & $\mathrm{x}$ & & $\mathrm{A}$ & $22.98(2.99)$ & $\mathrm{x}$ & \\
\hline B & $5.29(1.15)$ & & $\mathrm{x}$ & $\mathrm{B}$ & $13.79(2.16)$ & & $\mathrm{x}$ \\
\hline
\end{tabular}

The results from ANOVA as presented in Table 9 reveal that TS after $2 \mathrm{~h}$ as well as after $24 \mathrm{~h}$ immersion in water of board type B was significantly lower than that of board type A. This indicates that the less porous structure of the mat in the surface layers is more important than the resin content in terms of TS. As a result of the same resin content application in the surface layers, the amount of resin per unit of particle surface area in the surface layer of board type A ( $4 \mathrm{~mm}$ and $8 \mathrm{~mm}$ ) was higher than that of board type B (2 $\mathrm{mm}$ to $8 \mathrm{~mm}$ ). However, the TS of board type B was significantly lower than that of board type A.

It can be also seen from Fig. 13b that only board type B $(2 \mathrm{~mm}$ and $8 \mathrm{~mm})$ had the average TS value after $24 \mathrm{~h}$ immersion in water, meeting the requirement of moisture resistant particleboards according to the Australian/New Zealand standard AS/NZS 1859.1 (2017), part 1: Particleboard. 


\section{CONCLUSIONS}

1. The compression stiffness of the cotton stalk particle mat was increased with increasing particle size and decreased with increasing mat moisture content and temperature.

2. The plateau temperature at the core (centerline) of boards was not significantly different between mats having coarse particles and fine particles at the mat moisture content of $12 \%$ and $18 \%$. However, the plateau time of boards with coarse particles was considerably lower than that of boards with fine particles. Plateau time increased noticeably with increasing mat moisture content from $12 \%$ to $18 \%$ for both particle mats with coarse and fine particle sizes.

3. The particleboard with opening surface particle size of $2 \mathrm{~mm}$ (i.e. able to pass though the screen) had much better performance properties of MOR, MOE, IB, and TS than those of particleboard with opening surface particle size of $4 \mathrm{~mm}$. Consequently, a particle opening size of $2 \mathrm{~mm}$ is highly recommended for the surface layer for further studies on three-layered cotton stalk particleboard.

4. The particleboard having $2 \mathrm{~mm}$ opening particle size at the surface layers resulted in MOR, MOE, IB, and TS that met the minimum requirements of resistant particleboards according to the Australian/New Zealand standard AS/NZS 1859.1 (2017). However, to conclude that the particleboard met the full requirements of this standard, performance in a wet bending test needs to be evaluated.

\section{ACKNOWLEDGMENTS}

The authors acknowledge the Queensland Department of Agriculture and Fisheries for providing materials, technical staff, and access to manufacturing and testing. The first author would also like to thank the Australian Centre for International Agricultural Research (ACIAR) for providing a scholarship for higher education, which was undertaken as a component of the ACIAR Project FST/2016/151 "Advancing enhanced wood manufacturing industries in Laos and Australia”.

\section{REFERENCES CITED}

ANSI A208.1 (1999). "Particleboard," American National Standard Institute, Gaithersburg, MD, USA.

AS/NZS 1859.1 (2017). "Reconstituted wood-based panels - Specifications. Part 1:

Particleboard," Australian/New Zealand Standard, Sydney, Australia.

AS/NZS 4266.1 (2017). "Reconstituted wood-based panels - Methods of testing. Part 1:

Base panels," Australian/New Zealand Standard, Sydney, Australia.

Back, E. L., and Salmén, N. (1982). "Glass transition of wood components hold implication for molding and pulping processes," Journal of the Technical Association of the Pulp and Paper Industry 65(7), 107-110.

Cai, Z., Muehl, J. H., and Winandy, J. E. (2006). "Effects of panel density and mat moisture content on processing medium density fiberboard," Forest Products Journal 56(10), 20-25. 
Dai, C., and Wang, S. (2004). "Press control for optimized wood composite processing and properties Part 1: Pressing variables and sensors," in: Proceedings of Fundamentals of Composite Processing Workshop, U.S. Department of Agriculture, Forest Service, Forest Products Laboratory, Madison, WI, USA, pp. 54-64.

Dai, C., Wasylciw, W., and Jin, J. (2004). "Comparison of the pressing behaviour of wood particleboard and strawboard," Journal of the International Academy of Wood Science 38(7), 529-537. DOI: 10.1007/s00226-004-0256-2

Frazier, C. E. (2003). "Isocyanate wood binders," in: Handbook of Adhesive Technology, Taylor \& Francis Group, LLC, New York, NY, USA, pp. 1-14.

Fu, W. H. (1998). "Mat forming" in: Particleboards, China Forestry Publishing House of China, Beijing, China, pp. 209-236.

Glass, S. V., and Zenlinka, S. L. (2010). "Moisture content relation and physical properties," in: Wood Handbook - Wood as an Engineering Material (FPL-GTR190), U.S. Department of Agriculture, Forest Service, Forest Products Laboratory, Madison, WI, USA, pp. 4-19.

Guler, C., and Ozen, R. (2004). "Some properties of particleboards made from cotton stalks (Gossypium hirsutum L.)," Holz als Roh- und Werkstoff 62(1), 40-43. DOI: 10.1007/s00107-003-0439-9

Houts, J., Wang, S., Shi, H., Pan, H., and Kabalka, G. (2004). "Moisture movement and thickness swelling in oriented strandboard, part 1. Analysis using nuclear magnetic resonance microimaging," Journal of the International Academy of Wood Science 38(8), 617-628. DOI: 10.1007/s00226-004-0258-0

Kadja, K., Banna, M., Atcholi, K. E., and Sanda, K. (2011). "Utilization of bone adhesive to produce particleboards from stems of cotton plant at the pressing temperature of $140{ }^{\circ} \mathrm{C}$," American Journal of Applied Sciences 8(4), 318-322. DOI: 10.3844/ajassp.2011.318.322

Kamke, F. A. (2004). "Physics of hot pressing," in: Proceedings of Fundamentals of Composite Processing Workshop, U.S. Department of Agriculture, Forest Service, Forest Products Laboratory, Madison, WI, USA, pp. 3-18.

Li, L., Sun, J., and Jia, G. (2012). "Properties of natural cotton stalk bark fiber under alkali treating," J. Appl. Polym. Sci. 125(S2), E534-E539. DOI: 10.1002/app.36987

Nazerian, M., Beyki, Z., Gargarii, R. M., and Kool, F. (2015). "The effect of some technological production variables on mechanical and physical properties of particleboard manufactured from cotton (Gossypium hirsutum) stalks," Maderas. Ciencia Tecnologìa 18(1), 167-178. DOI: 10.4067/S0718-221X2016005000017

Nguyen, T. T., Bailleres, H., Redman, A., Leggate, W., Vandi, L., and Heiztmann, M. (2020). "Homogenous particleboard made from whole cotton (Gossypium hirsutum L.) stalk agricultural waste: Optimisation of particle size and influence of cotton residue on performance," BioResources 15(4), 7730-7748. DOI:

10.15376/biores.15.4.7730-7748

Rofii, M., Yamamoto, N., Ueda, S., Kojima, Y., and Suzuki, S. (2014). “The temperature behaviour inside the mat of wood-based panel during hot pressing under various manufacturing conditions," Official Journal of the Japan Wood Research Society 60(6), 414-420. DOI: 10.1007/s10086-014-1418-y

Soulama, S., Atcholi, K. E., Naon, B., Kadja, K., and Sanda, K. (2015). “Optimization of the implementation process and physical properties of cotton (Gossypium hirsutum) and Kenaf (Hibiscus cannabinus L.)," Engineering-London 7(12), 803-815. DOI: 10.4236/eng.2015.712070 
Tutus, A., Ezici, A., and Ates, S. (2010). "Chemical, morphological and anatomical properties and evaluation of cotton stalks (Gossypium hirsutum L.) in pulp industry," Scientific Research and Essays 5(12), 1553-1560. DOI: 10.5897/SRE.9000265

Wang, S., and Winistorfer, P. M. (2000). "The effect of species and species distribution on the layer characteristics of OSB," Forest Products Journal 50(4), 37-44.

Winandy, J. E., and Rowell, R. M. (2005). "Chemistry of wood strength," in: Handbook of Wood Chemistry and Wood Composites, ( ${ }^{\text {nd }}$ Ed.), CRC Press, Boca Raton, FL, USA, pp. 303-347. DOI: 10.1021/ba-1984-0207.ch005

Wong, E., Zhang, M., Wang, Q., and Kawai, S. (1998). "Effects of mat moisture content and press closing speed on the formation of density profile and properties of particleboard," Official Journal of the Japan Wood Research Society 44(4), 287-295. DOI: 10.1007/BF00581309

Article submitted: October 20, 2020; Peer review completed: December 27, 2020; Revised version received and accepted: April 26, 2021; Published: April 29, 2021.

DOI: 10.15376/biores.16.2.4149-4170 